\title{
Multimedia Appendix Correction: Patient Health Record Systems Scope and Functionalities: Literature Review and Future Directions
}

Lina Bouayad ${ }^{1,2^{*}}, \mathrm{PhD}$; Anna Ialynytchev ${ }^{2 *}, \mathrm{PhD}$; Balaji Padmanabhan ${ }^{3 *}, \mathrm{PhD}$

\footnotetext{
${ }^{1}$ Department of Information Systems and Business Analytics, Florida International University, Miami, FL, United States

${ }^{2}$ Health Services Research and Development Service, Center of Innovation on Disability and Rehabilitation Research, Tampa, FL, United States

${ }^{3}$ Department of Information Systems and Decision Sciences, University of South Florida, Tampa, FL, United States

*all authors contributed equally
}

Corresponding Author:

Lina Bouayad, PhD

Department of Information Systems and Business Analytics

Florida International University

11200 SW 8th Street

Miami, FL, 33199

United States

Phone: 13053485437

Email: $\underline{\text { bouayad@fiu.edu }}$

\section{Related Article:}

Correction of: https://www.jmir.org/2017/11/e388

(J Med Internet Res 2019;21(9):e15796) doi: 10.2196/15796

The authors of "Patient Health Record Systems Scope and Functionalities: Literature Review and Future Directions" (J Med Internet Res 2017;19(11):e388) have replaced Multimedia Appendix 1 with a new file. Because of formatting issues, the original appendix was missing data elements in the table. Published here is a new version of Multimedia Appendix 1 with all data elements.
The corrections will appear in the online version of the paper on the JMIR website on September 5, 2019, together with the publication of this correction notice. Because this was made after submission to PubMed, PubMed Central, and other full-text repositories, the corrected article also has been resubmitted to those repositories.

\section{Multimedia Appendix 1}

Patient data elements reported in the literature.

[PDF File (Adobe PDF File), $90 \mathrm{~KB}-$ Multimedia Appendix 1]

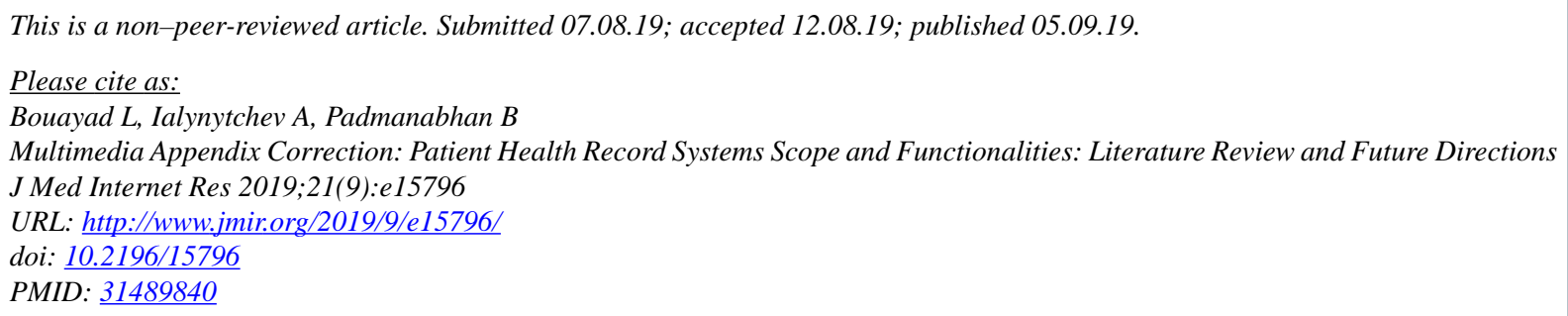

CLina Bouayad, Anna Ialynytchev, Balaji Padmanabhan. Originally published in the Journal of Medical Internet Research (http://www.jmir.org), 05.09.2019. This is an open-access article distributed under the terms of the Creative Commons Attribution License (https://creativecommons.org/licenses/by/4.0/), which permits unrestricted use, distribution, and reproduction in any medium, provided the original work, first published in the Journal of Medical Internet Research, is properly cited. The complete bibliographic information, a link to the original publication on http://www.jmir.org/, as well as this copyright and license information must be included. 